\title{
CARACTERIZAÇÃO BROMATOLÓGICA E MINERAL DOS RESÍDUOS DE BROTO DE BAMBU, VISANDO A SUA UTILIZAÇÃo COMO ALIMENTO ANimAL( $\left.{ }^{1}\right)$
}

\author{
ANISIO AZZINI $\left({ }^{2,6}\right)$, PAULO ROBERTO LEME $\left({ }^{3}\right)$, \\ CASSIA REGINA LIMONTA CARVALHO $\left({ }^{4}\right)$, ANTONIO LUIZ \\ DE BARROS SALGADO $\left({ }^{2}\right)$ e VERA LÚCIA PUPPO FERREIRA $\left({ }^{5,6}\right)$
}

\begin{abstract}
RESUMO
Nesse estudo, realizado em 1992, nos Institutos Agronômico, de Tecnologia de Alimentos e de Zootecnia, procedeu-se à caracterização bromatológica e mineral dos resíduos de broto de bambu (Dendrocalamus giganteus Munro), a fim de utilizá-los como alimento animal. Os resultados mostraram que tais resíduos, constituídos basicamente por bainhas e pedaços tenros de colmo, apresentaram elevados teores de proteína $(131,4 \mathrm{~g} / \mathrm{kg})$, açúcares $(115,3 \mathrm{~g} / \mathrm{kg})$, fibras $(235,4 \mathrm{~g} / \mathrm{kg})$ e ácido cianídrico $(213 \mathrm{mg} / \mathrm{kg}$ ). Essa concentração de ácido cianídrico pode causar efeito tóxico em animais, devendo-se, portanto, eliminá-lo, adotando o mesmo procedimento utilizado para a fração comestível do broto, o qual se resume no cozimento em água fervente durante 20 minutos. Após esse tratamento, os resíduos de broto de bambu podem ser utilizados como alimento animal.
\end{abstract}

Termos de indexação: broto de bambu, Dendrocalamus giganteus Munro, análise química, alimentação animal.

( ${ }^{1}$ Recebido para publicação em 28 de março de 1994 e aceito em 19 de abril de 1995

(2) Seção de Plantas Fibrosas, Instituto Agronômico (IAC), Caixa Postal 28, 13001-970 Campinas (SP).

$\left(^{3}\right)$ Seção de Criação e Manejo de Gado de Corte, Instituto de Zootecnia (IZ), Caixa Postal 60, 13460-000 Nova Odessa (SP).

( ${ }^{4}$ Seção de Glícides, Instituto de Tecnologia de Alimentos (ITAL), Caixa Postal 139, 13073-001 Campinas (SP).

(5) Seção de Controle de Qualidade, ITAL.

(6) Com bolsa de pesquisa do CNPq. 


\title{
ABSTRAC'T \\ MINERAL AND BROMATOLOGIC CHARACTERIZATION OF BAMBOO SHOOT RESIDUES AS ANIMAL FOOD
}

\begin{abstract}
The mineral and bromatologic characterization of bamboo shoot residues (Dendrocalamus giganteus Munro) were determined as animal food. The results showed that the bamboo shoot residues (sheaths and pieces of soft culms) presented hight contents of protein $(131.4 \mathrm{~g} / \mathrm{kg})$, sugars $(115.3 \mathrm{~g} / \mathrm{kg})$, fibers $(235.4 \mathrm{~g} / \mathrm{kg})$ and hydrocyanic acid $(213 \mathrm{mg} / \mathrm{kg})$. This hydrocyanic acid concentration can be toxic for animals, then this cyanogenic componed must be eliminated using boiling water during 20 minutes. This treatment is similar to the treatment used for edible parts of bamboo shoot. After this treatment for hydrocyanic acid elimination the bamboo shoot residues can be used as animal food.
\end{abstract}

Index terms: bamboo shoot, Dendrocalamus giganteus Munro, chemical analyses, animal food.

Nos países do Continente Asiático, a produção de broto de bambu é uma atividade agrícola comum, com grande significado econômico, pois, além de ser largamente consumido como alimento natural, tem sido industrializado e exportado. No Japão, em 1979, a produção de broto de bambu foi de 150.000 $\mathrm{t}$, para um consumo de $198.200 \mathrm{t}$ (Ueda, 1981); na China, nesse mesmo ano, foi de $215.000 \mathrm{t}$ (Wu, 1981). Na Tailândia, Bhodthipuks (1981) observou que o rendimento líquido por hectare, obtido com a produção de broto da espécie Dendrocalamus asper, foi de 700 dólares.

No Brasil, o hábito de consumir o broto de bambu como alimento não é muito difundido. Entretanto, nas grandes cidades, principalmente paulistas, o consumo desse produto vem aumentando significativamente, em função não só dos restaurantes chineses e japoneses, mas, também, da mudança de hábito alimentar de toda a população.

A produção de broto de bambu constitui, sem dúvida alguma, alternativa promissora para nossa agricultura, uma vez que se assemelha ao palmito tradicional, obtido da espécie Euterpe edulis.

No preparo do broto para consumo, obtém-se grande quantidade de resíduos, eliminados como rejeitos, sem nenhuma utilização. Este estudo objetivou determinar as características bromatológicas e minerais desses resíduos, a fim de utilizá-los como alimento para animais.

\section{Material e Métodos}

Utilizaram-se resíduos de broto da espécie Dendrocalamus giganteus Munro, por ser a mais cultivada para a produção de broto de bambu. Esses resíduos, constituídos basicamente por bainhas e pedaços tenros de colmo, foram, de início, secos em estufa a $60-70^{\circ} \mathrm{C}, \log o$ após, triturados em moinho de martelos e, a seguir, utilizados nas várias determinações bromatológicas e minerais: os teores de proteína, açúcares, tanino, cinzas e ácido cianídrico, conforme Horwitz (1980); a quantidade de fibras e de lipídios, de acordo com Diemair (1963), e a concentração mineral com relação a $\mathrm{P}, \mathrm{Ca}, \mathrm{Mg}, \mathrm{Fe}, \mathrm{Cn}, \mathrm{Zn}, \mathrm{Mn}$, $\mathrm{Na}$ e K, segundo Angelucci \& Mantovani (1968). Tais dados foram obtidos em delineamento inteiramente casualizado, com três repetições, conforme Pimentel Gomes (1977).

\section{Resultados e Discussão}

Os resultados da análise brotamotógica dos resíduos de broto de bambu da espécie Dendrocalamus giganteus constam do quadro 1.

O teor de proteína desse resíduo $(131,4 \mathrm{~g} / \mathrm{kg})$ é semelhante ao do farelo de arroz $(135,0 \mathrm{~g} / \mathrm{kg})$ e superior ao do milho em grãos $(100,0 \%)$, conforme Moreira (1983).

Os resíduos de broto de bambu, ricos em açúcares $(115,3 \mathrm{~g} / \mathrm{kg})$, apresentam cheiro adocicado bastante agradável e coloração parda. 
Quadro 1. Análise bromatológica dos resíduos de broto de bambu da espécie Dendrocalamus giganteus $\left({ }^{1}\right)$

\begin{tabular}{lccc}
\hline Análise & Média & Desvio-padrão & C.V. \\
\hline Proteína $(\mathrm{g} / \mathrm{kg})$ & 131,4 & 1,6 & 1,22 \\
Açúcares totais $(\mathrm{g} / \mathrm{kg})$ & 115,3 & 2,6 & 2,25 \\
Açúcares redutores $(\mathrm{g} / \mathrm{kg})$ & 103,1 & 1,8 & 1,75 \\
Fibras $(\mathrm{g} / \mathrm{kg})$ & 235,4 & 2,7 & 1,15 \\
Lipídios $(\mathrm{g} / \mathrm{kg})$ & 17,8 & 1,1 & 6,18 \\
Cinzas $(\mathrm{g} / \mathrm{kg})$ & 63,6 & 0,3 & 0,47 \\
Tanino $(\mathrm{mg} / 100 \mathrm{~g})$ & 1,468 & 34 & 2,32 \\
Ácido cianídrico $(\mathrm{mg} / 100 \mathrm{~g})$ & 213 & 18 & 8,45 \\
Carboidratos totais $(\mathrm{g} / \mathrm{kg})\left({ }^{2}\right)$ & 787,2 & - & -- \\
\hline
\end{tabular}

( ${ }^{1}$ Valores calculados sobre a massa seca da amostra. $\left({ }^{2}\right)$ Calculado por diferença segundo a equação: 1000 - (proteína bruta + lipídios + cinzas).

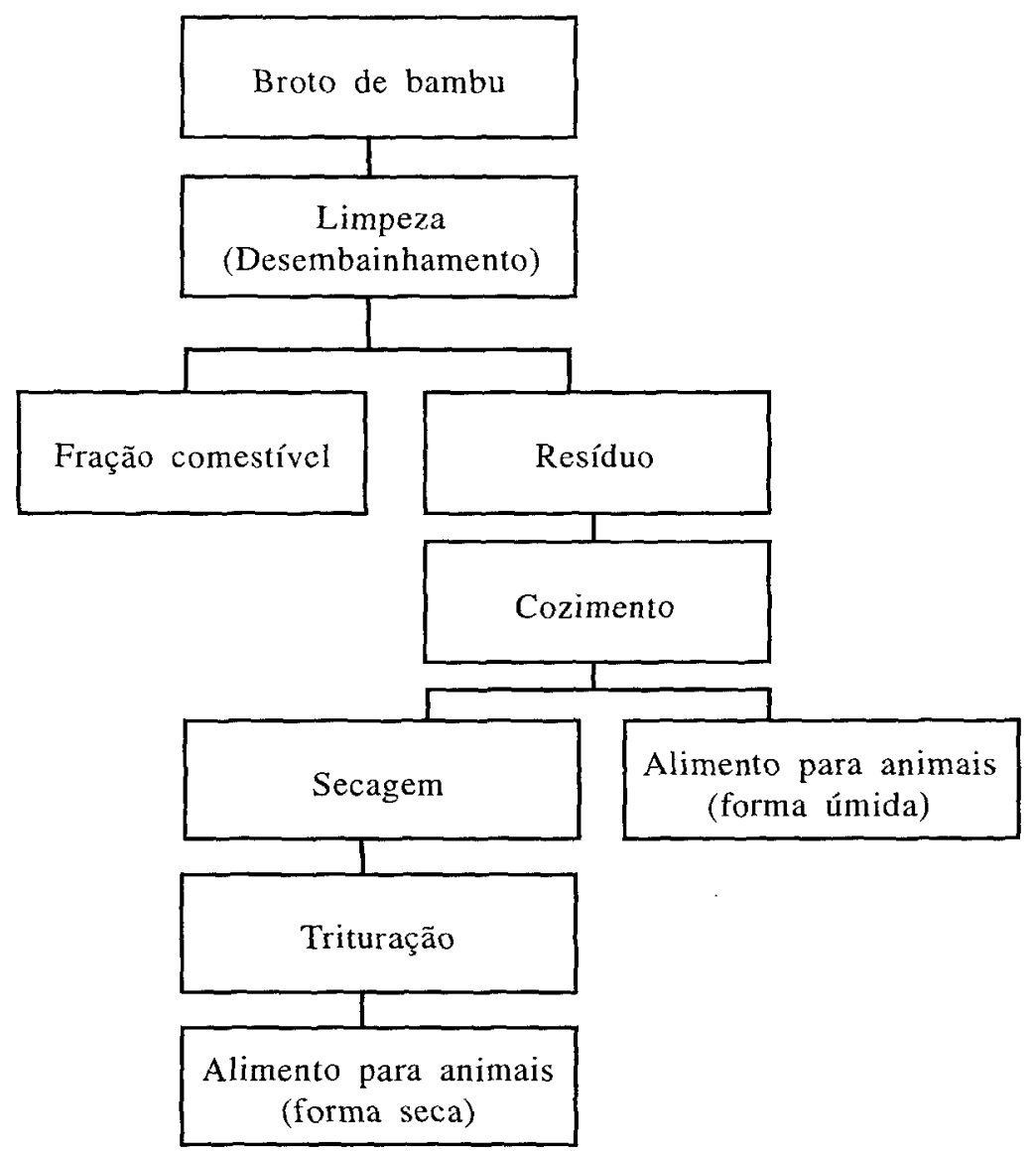

Figura 1. Esquema para obtenção de alimento para animais a partir de resíduos de broto de bambu da espécie Dendrocalamus giganteus Munro. 
Quadro 2. Análise mineral dos resíduos de broto de bambu da espécie Dendrocalamus giganteus $\left({ }^{1}\right)$

\begin{tabular}{|c|c|c|c|}
\hline Minerais & Média & Desvio-padrão & C.V. \\
\hline Fósforo $(\mathrm{mg} / 100 \mathrm{~g})$ & 261,00 & 2,60 & 0,99 \\
\hline Cálcio $(\mathrm{mg} / 100 \mathrm{~g})$ & 53,40 & 2,09 & 3,91 \\
\hline Magnésio $(\mathrm{mg} / 100 \mathrm{~g})$ & 107,60 & 0,61 & 0,57 \\
\hline Ferro $(\mathrm{mg} / 100 \mathrm{~g})$ & 11,00 & 0,32 & 2,91 \\
\hline Cobre $(\mathrm{mg} / 100 \mathrm{~g})$ & 1,08 & 0,04 & 3,70 \\
\hline Zinco $(\mathrm{mg} / 100 \mathrm{~g})$ & 4,89 & 0,19 & 3,89 \\
\hline Manganês (mg/100 g) & 2,29 & 0,08 & 3,49 \\
\hline Sódio $(\mathrm{mg} / 100 \mathrm{~g})$ & 2,55 & 0,40 & 15,68 \\
\hline Potássio $(\mathrm{mg} / 100 \mathrm{~g})$ & 2,85 & 101,00 & 3,54 \\
\hline
\end{tabular}

( $\left.{ }^{1}\right)$ Valores calculados sobre a massa seca.

Quanto aos níveis de lipídios $(17,8 \mathrm{~g} / \mathrm{kg})$, cinzas $(63,6 \mathrm{~g} / \mathrm{kg})$, fibras $(235,4 \mathrm{~g} / \mathrm{kg})$ e taninos $(1.468$ $\mathrm{mg} / 100 \mathrm{~g}$ ), não constituem fatores limitantes à utilização desse material na alimentação animal.

O ácido cianídrico $(213 \mathrm{mg} / \mathrm{kg})$, no nível observado, pode causar efeito tóxico, conforme Blood et al. (1979). Segundo esses autores, a dose altamente tóxica do ácido cianídrico se aproxima de 6.000 $\mathrm{mg} / \mathrm{kg}$, embora o grau de toxicidade em determinada espécie animal varie em função de diversos fatores: desde a concentração do ácido cianídrico até a velocidade de consumo do alimento.

O ácido cianídrico nos resíduos de broto de bambu pode ser totalmente eliminado, adotando-se o mesmo procedimento utilizado para sua fração comestível: cozimento em água fervente, durante 20 minutos. Esse tratamento, segundo Ferreira et al. (1991), elimina completamente o composto cianogênico original do broto de bambu, que é a taxifilina. Esse composto se desdobra, sob a ação do calor através da hidrólise, em glicose, hidroxibenzaldeído e ácido cianídrico, segundo Schwarzmaier, citado por Ferreira et al. (1991).

Após o tratamento, que elimina o princípio tóxico do broto de bambu, seus resíduos podem ser fornecidos aos animais, principalmente bovinos, tanto na forma seca como na úmida, conforme figura 1 . $\mathrm{Na}$ forma úmida, esses resíduos devem ser utilizados em local relativamente próximo do centro de produção, como ocorre com os de cevada na produção de cerveja. Na forma seca, pode-se empregá-los na composição de rações. Quanto à análise mineral dos resíduos do broto de bambu - Quadro 2 - verifica-se que os resultados não apresentaram níveis incompatíveis: o teor de potássio, embora seja elevado (2.855 mg/100 g), ć menor que aqueles observados nos melaços de beterraba $(4.770 \mathrm{mg} / 100 \mathrm{~g})$ e citros (3.670 mg/100 g) (Morrison, 1966).

Para os demais componentes minerais, existem variações que se aproximam dos valores observados nos mais variados tipos de alimentos, tanto na forma de silagens, como nos concentrados ou forragens, conforme dados fornecidos por Morrison (1966).

\section{REFERÊNCIAS BIBLIOGRÁFICAS}

ANGELUCCI, E. \& MANTOVANI, D.M.B. Minerais em alimentos. ITAL, Campinas, 1968. $131 \mathrm{p}$.

BHODTHIPUKS, P. Bamboo plantation in Thailand. In: XVII IUFRO WORLD CONGRESS, Kyoto, 1981. Proceedings. Kyoto, Wood Research Institute/Kyoto University, 1981. p.165-168. 
BLOOD, D.C.; HENDERSON, J.A. \& RADOSTITIS, O.M. Veterinary Medicine. 5.ed. Baillière Tindall, London, 1979. 1135p.

DIEMAIR, W. Laboratirunsbuch für Lebensnuttelchemiker. Verlag von Teodor Steinkoptt, Dresden. 8. Anflage, 1963.

FERREIRA, V.L.P; MARSSAIOLI, A.J. \& IADEROSA, M. Métodos simplificados para identificação e deteç̧āo de taxifilina no broto de bambu (Dendrocalamus giganteus Munro). Coletânea do ITAL, Campinas, 21(1):57-63, 1991.

HORWITZ, W. Official methods of analysis of the Association of Official Analytical Chemists, Washington, D.C. 13.ed. 1980. 1.018p.

MOREIRA, A.H. Suplementos de concentrados para vacas leiteiras. EMBRATER, 1983. 14p.
MORRISON, F.B. Alimentos e alimentaçäo dos animais. 2.ed. Edições Melhoramentos, 1966. 892p.

PIMENTEL GOMES, F.P. Curso de estatística experimental. 7.ed. ESALQ, Piracicaba, 1977. 430p.

SCHWARZMAIER, V. Cyanogenesis of Dendrocalamus: Taxiphyllin. Phytochemistry, Oxford, 16:1.599. $1.600,1977$

UEDA, K. Bamboo industry in Japan, present and future. In: XVII IUFRO WORLD CONGRESS, Kyoto, 1981. Proceedings. Kyoto, Wood Research Institute/Kyoto University, 1981. p.2-14.

WU, S.C. Research and development of the production and utilization of bamboo in Taiwan, R.O.C. In: VII IUFRO WORLD CONGRESS, Kyoto, 1981. Proceedings. Kyoto, Wood Research Institute/Kyoto University, 1981. p.45-50. 